\title{
Gespreksmodellen in de verzekeringsgeneeskunde
}

\author{
W.E.L. de Boer • J.H.L. Wijers • J. Spanjer • I. van \\ der Beijl • W. Zuidam • A. Venema
}

\begin{abstract}
Het meest gebruikte instrument voor de WAObeoordeling, het beoordelingsgesprek, is zeer matig ontwikkeld. De druk op een valide en betrouwbare beoordeling zal nog sterker toenemen als de plannen van het kabinet doorgang vinden. Er bestaan wel aanzetten tot de ontwikkeling van een valide instrument in de vorm van modellen voor gespreksvoering. Deze worden in dit artikel beschreven: welke bestaan er, waarop ze zijn gebaseerd, wat zijn de overeenkomsten en verschillen? Gevonden zijn de belastbaarheid gerichte beoordeling, het Methodisch BeoordelingsGesprek en de MultiCausale Analyse. Onderzocht is wat de gemeenschappelijke principes en praktijken van deze modellen zijn en wat de technische en principiële verschillen zijn. De modellen blijken alle te zijn gebaseerd op de ervaring van toepassers en geen van alle goed gevalideerd. Ze zijn alle gebaseerd op een complex van juridische, medische en psychologische uitgangspunten. Verschillen tussen de modellen van gespreksvoering blijken minder groot dan de overeenkomsten. De door de opstellers gehanteerde uitgangspunten worden besproken tegen de achtergrond van wetenschappelijke literatuur. Er zijn voornamelijk indirecte argumenten voor de aangenomen uitgangpunten. Door middel van ontwikkeling en onderzoek in de praktijk kan dit deel van het vak op een hoger niveau van professionaliteit worden gebracht.
\end{abstract}

W.E.L. de Boer $(\square)$

W.E.L. de Boer en A. Venema zijn onderzoeker bij TNO; I. van der Beijl en W. Zuidam destijds TNO; J.H.L. Wijers is verzekeringsarts en bedrijfsarts WOSM; J. Spanjer is verzekeringsarts UWV.Correspondentieadres: W.E.L. de Boer, TNO Kwaliteit van Leven, postbus 718, 2130 AS Hoofddorp E-mail: w.dboer@arbeid.tno.nl
Keywords claimbeoordeling · gespreksmodellen . beoordelingsgesprek · verzekeringsgeneeskunde

De beoordelingen door verzekeringsartsen staan bloot aan kritiek. ${ }^{1}$ Of het vaak fout gaat in de praktijk, of er onredelijk streng of juist veel te soepel wordt beoordeeld, is bij ons weten niet onderzocht. Diverse onderzoeken hebben wel aannemelijk gemaakt dat er spreiding bestaat in oordelen. ${ }^{2}-5$ De beoordeling wordt in het algemeen gebaseerd op voorinformatie, gesprek, lichamelijk onderzoek en eventueel nadere onderzoeken. In de dagelijkse praktijk van de WAO-beoordeling wordt, voor het medische deel, zwaar geleund op het gesprek met de cliënt. ${ }^{6}{ }^{8}$ Opmerkelijk is dat dit onderdeel van de beoordeling zo weinig is onderbouwd met wetenschappelijk onderzoek.

Naar het zich laat aanzien zal de druk op het beoordelingsgesprek toenemen bij claims op de WIA, de Wet Inkomen naar Arbeidsvermogen. ${ }^{9}$ Weliswaar zal de informatie in die beoordelingen meer komen uit reïntegratie verslagen (waarin informatie van specialisten) dan nu het geval is, maar de vraag naar volledigheid en duurzaamheid zal toch voor een belangrijk deel moeten worden beantwoord met informatie uit het gesprek. ${ }^{10}$ Een robuust onderzoeksinstrument in de vorm van een gevalideerd en bewezen effectief gespreksmodel zou dus in een belangrijke behoefte kunnen voorzien. Dat bestaat echter nog niet.

Aanzetten voor gespreksmodellen in het kader van de WAO zijn wel gedaan. ${ }^{11}{ }^{15}$ Onder gespreksmodellen verstaan we schematische voorschriften over gespreksvoering die tenminste de organisatie van de topics in het gesprek beschrijven en ook de techniek van de gespreksvoering. ${ }^{16}$ De gespreksmodellen in het kader van de 
WAO zijn niet gebaseerd op wetenschappelijke theorie. Ook zijn ze vrijwel niet aan onderzoek naar effectiviteit, validiteit en betrouwbaarheid onderworpen. Spanjer ${ }^{17,18}$ heeft onderzoek gedaan naar de reproduceerbaarheid en de inter- en intra-beoordelaarsbetrouwbaarheid van WAO-beoordelingen. Hij constateerde dat de betrouwbaarheid van beoordeling op basis van een videopresentatie van de BelastbaarheidsGerichte Beoordeling (BGB) in een laboratoriumsituatie goed was, maar in de praktijk waarschijnlijk lager. Artsen vroegen zijns inziens vaak onvoldoende door en gaven te veel aandacht aan medische zaken en ziekte. De gespreksmodellen zijn onderdeel van de beoordelingen als geheel. De plaats van de modellen is aangegeven in het advies van de Raad van Gezondheidsonderzoek ${ }^{8}$ inzake de verzekeringsgeneeskunde: het zijn modellen van informatieverzameling die zijn gekoppeld aan modellen van bewijsvoering. Van die laatste staan er in het RGO-advies twee beschreven: de argumentatieve claimbeoordeling en het verzekeringsgeneeskundige referentiekader. Gespreksmodellen die voortbouwen op het verzekeringsgeneeskundige referentiekader hebben we niet aangetroffen. In het buitenland hebben noch via PubMed, noch via eigen onderzoek ${ }^{19}$ gespreksmodellen voor de claimbeoordeling gevonden.

In dit artikel richten we ons op de vragen:

1. Wat zijn de overeenkomsten en verschillen tussen de gepubliceerde modellen?

2. Waar zijn ze op gebaseerd?

\section{METHODE}

Door het bestuderen van de beschrijvingen van gepubliceerde modellen en interviews met ontwikkelaars van die modellen werden kenmerken, uitgangspunten en pretenties van de verschillende 17 modellen uitgewerkt en vergelijkbaar gemaakt (vraagstelling 1). Die interviews vonden plaats in verschillende rondes. Eerst werden gezamenlijk met alle ontwikkelaars de concepten ontwikkeld die vervolgens in bilaterale interviews werden verdiept. Daarna werden in een gezamenlijk overleg de resultaten getoetst. Deze werkwijze was nodig omdat bleek dat de opstellers ieder hun eigen termen gebruiken waardoor er soms meer overeenstemming was dan uit de schriftelijke beschrijvingen naar voren kwam.

Van de gevonden verschillen en overeenkomsten in uitgangspunten werd nagegaan waar ze op gebaseerd waren (vraagstelling 2). In de literatuur (Tijdschrift voor Bedrijfs- en Verzekeringsgeneeskunde, PubMed en Psychinfo) werd per uitgangspunt gezocht naar theorieën en modellen die ondersteunend zouden kunnen zijn bij de ontwikkeling en toetsing van de modellen.

\section{RESULTATEN VRAAGSTELLING 1: WELKE MODELLEN ZIJN ER?}

Het eerste gespreksmodel dat is geïntroduceerd in de verzekeringsgeneeskunde en in de opleiding tot verzekeringsarts is het Methodisch BeoordelingsGesprek (MBG). ${ }^{11,13}$ Verder is er de Belastbaarheids-Gerichte Beoordeling (BGB) ${ }^{14}$ die is ontwikkeld als reactie op het $\mathrm{MBG}$ vanwege de verondersteld geringe flexibiliteit van het MBG en onvoldoende gerichtheid op het beoordelen van de items van het belastbaarheidpatroon. Ten slotte is er de MultiCausale Analyse (MCA) ${ }^{12,15}$ eveneens een reactie op het $\mathrm{MBG}$ vanwege de verondersteld geringe flexibiliteit en op de veronderstelde problemen van cliënten om in het begin van het gesprek goed de claimklacht te kunnen verwoorden. Onderstaand geven we ze op hoofdlijnen weer, een systematische vergelijking staat in tabel 1 . Voor details verwijzen we naar de oorspronkelijke publicaties.

\section{Methodisch BeoordelingsGesprek}

Hoofdprincipe is de argumentatieve claimbeoordeling: ${ }^{8}$ claim en argumenten van de cliënt worden als te toetsen en aan te vullen uitgangspunt genomen, met nadruk op de beperkingen en de mogelijkheden van de cliënt. De cliënt is zelf als eerste verantwoordelijk voor een toelichting op de claim, voor de arbeidsongeschiktheid en het herstelgedrag. Er wordt zodoende gestreefd naar gelijkwaardigheid tussen cliënt en verzekeringsarts. Getest wordt of de cliënt deze verantwoordelijkheid kan en wil dragen. De methode is semi gestructureerd met volledigheid als oogmerk. Er worden gespreksregels gesteld in de vorm van een volgorde van vragen en de rol van de cliënt. De afwijkingen ervan, in de vorm van spontane opmerkingen en inadequate antwoorden, worden opgevat als uitslagen van de test.

| In de verzekeringsgeneeskunde zijn drie protocollen gepubliceerd voor het beoordelingsgesprek.

| Deze protocollen zijn gebaseerd op juridische, medische en psychologische uitgangspunten.

Op onderdelen zijn deze protocollen verschillend, op onderdelen ook zeer vergelijkbaar. Alle protocollen zijn experience based en behoeven validering in de praktijk.

Er worden twaalf topics onderscheiden die moeten worden bevraagd. De methodebeschrijving bevat veel instructies over de wijze van behandeling van de topics en concrete formuleringen. Elk topic wordt afgesloten met een samenvatting. De samenvattingen dienen als bouwstenen voor de conclusie. Plausibiliteit, interne consistentie en consistentie met sociaal wetenschappelijke en 
Tabel 1 Vergelijkingen tussen groepsmodellen in de verzekeringsgeneeskunde

\begin{tabular}{|c|c|}
\hline & BGB \\
\hline $\begin{array}{l}\text { Typisch voor } \\
\text { model }\end{array}$ & $\begin{array}{r}\text { Doorvragen naar concrete en } \\
\text { gedetailleerde voorbeelden van } \\
\text { beperkingen/belemmeringen en } \\
\text { mogelijkheden. } \\
\mid \text { Sterke structuur } \\
\text { Alle onderwerpen moeten } \\
\text { behandeld } \\
\text { worden, maar willekeurige volgorde }\end{array}$ \\
\hline Topics & $\begin{array}{r}\text { - Werk } \\
\text { - Ziekte gegevens } \\
\text { - Ervaren beperkingen en } \\
\text { belemmeringen } \\
\text { - Activiteiten/ Handicaps } \\
\text { - Visie cliënt (geschikt voor eigen } \\
\text { werk of lichter werk?) } \\
\text { - Onderzoek } \\
\text { - Visie verzekeringsarts }\end{array}$ \\
\hline Introductie & $\begin{array}{r}\text { | Doel gesprek uitleggen } \\
\text { Gang van zaken uitleggen } \\
\text { |Samenvatten dossier } \\
\text { | Weerstanden wegnemen }\end{array}$ \\
\hline $\begin{array}{l}\text { Belangrijkste } \\
\text { punten van }\end{array}$ & $\begin{array}{r}\text { Alle onderwerpen moeten } \\
\text { besproken }\end{array}$ \\
\hline het gesprek & worden \\
\hline
\end{tabular}

Afsluiting

Mate van structuur

Duur gesprek

Toetsen op waarheid

(Consistentie en plausibiliteit van de

argumentatieve claimbeoordeling)
| Vraag of cliënt nog aanvullingen heeft

Oordeel van de arts en mogelijke consequenties

| Uitleg verdere gang van zaken

Sterk gestructureerd, met name bij

het

onderwerp beperkingen en

belemmeringen.

Half uur - drie kwartier

Vragen naar concrete en gedetailleerde voorbeelden, deze moeten consistent zijn

Consistentie tussen alle nagevraagde

onderwerpen én tussen het verhaal gegevens

Gezond verstand Verzekeringsarts moet overtuigd zijn gesprekstechniek van de cliënt en de verkregen

MBG MCA

| Veelvuldig gebruik van samenvattingen

| Uitvragen van de negen verschillende onderwerpen. Elke beoordeling heeft een eenduidig begin (werk, claim en claimklachten, ander werk)

| Dagverhaal** wordt als opdracht gegeven

Sterke structuur

Negeren spontane opmerkingen cliënt $* * *$

Corrigeren inadequate antwoorden cliënt $* * * *$ claimitems - werk

- claim en claimklachten - ander werk

Toetsingsitems* - motivatie

- eigen ziekteleer

- fitheid \& vitaliteit

- verandering, mentaal/persoonlijk

- life-events

- toekomst

- Onderzoek

Doel gesprek uitleggen

Spelregels vaststellen (eerst uw mening over de actualiteit en daarna andere zaken)

Agenda bespreken Alle onderwerpen moeten besproken

worden met minimaal één oriënterende hoofdvraag

Vraag of de cliënt nog aanvullingen

heeft

| Slotsamenvatting Conclusie

| Eventuele vervolgafspraken

Sterk gestructureerd bij de eerste drie te bespreken onderwerpen, de claimitems

Drie kwartier

- Door middel van structuur en gericht doorvragen

vast onderdeel van het model na elk
| Duidelijk aansluiten bij de cliënt, cliënt moet zich gehoord voelen (goede communicatie is essentieel)

Alle zes de onderwerpen moeten behandeld worden, maar de volgorde is vrij en de onderwerpen lopen door

elkaar

| Veel doorvragen en inspelen op opmerkingen van de cliënt

- Gezondheid

- Werk

- Privé

- Functioneren

- Persoon

- Onderzoek

(Visie cliënt komt terug in

bovengenoemde

onderwerpen)

Korte uitleg gang van zaken

Korte samenvatting dossier Snel in gesprek met cliënt

| Alle onderwerpen moeten besproken worden

| Terugkoppelen van beperkingen en belemmeringen naar de cliënt Ruimte voor opmerkingen van de cliënt en ingaan op nieuwe opmerkingen of dingen die zijn blijven liggen | Afspraken en planning Geen sterke structuur

Half uur - drie kwartier

| Verzamelen van gegevens door het na- en doorvragen van alle onderwerpen

Consistentie van het verhaal cliënt

In tweede instantie aanvullende informatie van derden

gesprekstechniek 
Tabel 1 (continued)

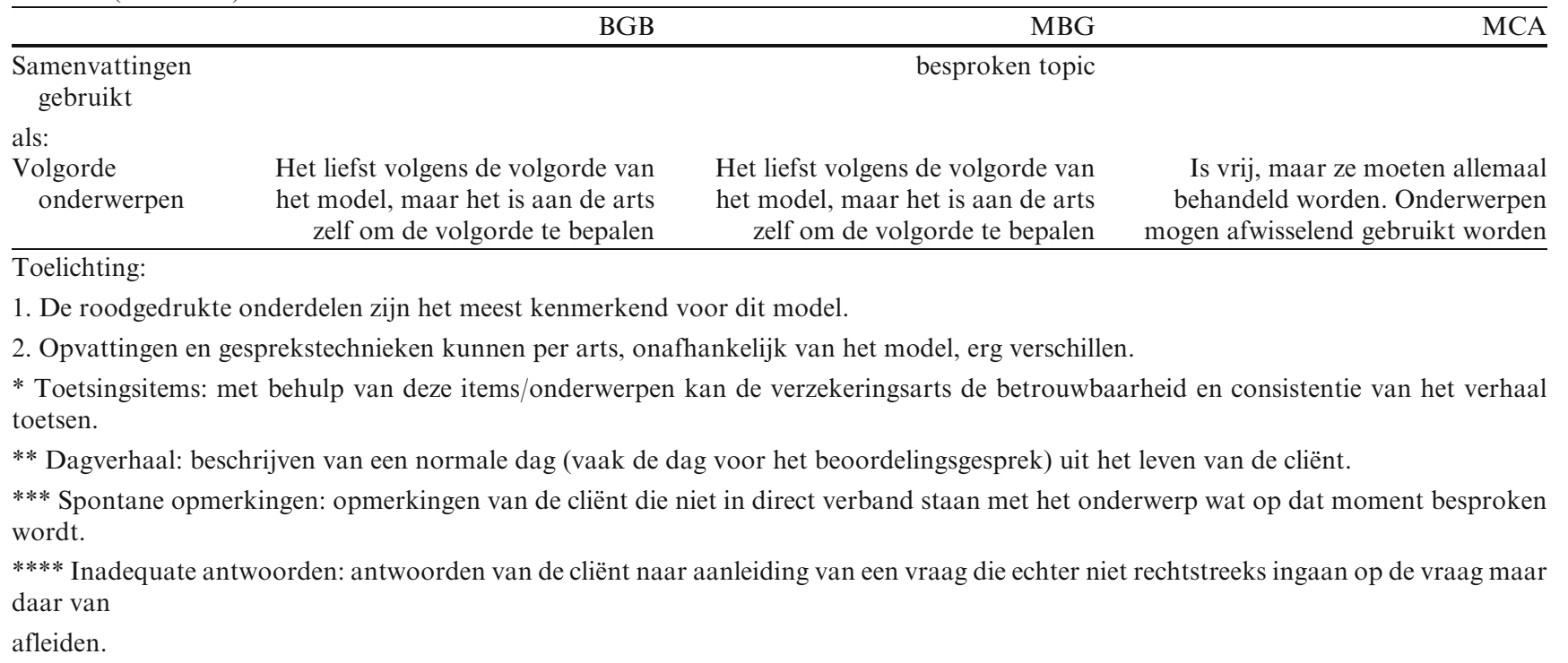

medische inzichten dienen als toetsingscriteria. De verzekeringsarts geeft een eindsamenvatting, een onderbouwing en een oordeel. Doel is te komen tot systematische beoordeling, gebaseerd op zoveel mogelijk controleerbare feiten.

\section{BelastbaarheidsGerichte Beoordeling}

Ook hier geldt het principe van de argumentatieve claimbeoordeling: ${ }^{8}$ veel aandacht is er voor het verschil tussen de huidige situatie en het premorbide niveau (als operationalisatie van ziekte of gebrek). Voorbeelden van ervaren belemmeringen en nog wel ondernomen activiteiten (concreet en gedetailleerd en bij voorkeur spontaan door de cliënt gegeven) spelen een belangrijke rol om simulatie/aggravatie te bemoeilijken en het invullen van het belastbaarheidpatroon te vergemakkelijken. Het gesprek is semi-gestructureerd. De topics liggen vast maar de volgorde waarin ze aan de orde komen kan verschillen. Pas als alle gegevens zijn verzameld wordt een oordeel geveld door de verzekeringsarts en dit oordeel wordt duidelijk aan de cliënt medegedeeld. Doel is te komen tot een systematische beoordeling, gericht op datgene wat er daadwerkelijk in de praktijk beoordeeld moet worden.

\section{MultiCausale Analyse}

Ook hier is het onderliggende principe de argumentatieve claimbeoordeling. De nadruk ligt op het in kaart brengen van belemmerende en motiverende factoren bij de cliënt. Daarbij wordt ook gevraagd naar psychische en sociale aspecten van de cliënt.
Het opbouwen van een vertrouwensrelatie wordt hiervoor gezien als voorwaarde. Aansluiting bij de invalshoek van de cliënt leidt tot openheid in het gesprek. De verzekeringsarts heeft bij voorkeur een attitude van betrokkenheid, respect en aandacht waarin voldoende wordt doorgevraagd en subjectieve aspecten worden meegewogen.

De MCA is een heuristische aanpak met grote vrijheid voor de arts. De topics liggen wel vast, maar deze zijn globaal beschreven in velden. De methode is in beperkte mate gestructureerd: het gesprek mag dynamisch zijn, met switchen tussen velden op geleide van spontane opmerkingen van de cliënt. Doorvragen geeft inzicht in ernst, plausibiliteit en consistentie. Delen van de claim van de cliënt kunnen overal in het gesprek aan de orde komen. Er wordt veel belang gehecht aan de beleving van de cliënt. Daarbij is doorvragen essentieel. Het doel is een begrijpende beoordeling: beeldvorming en besluitvorming zijn onderling verweven. Het oordeel wordt duidelijk aan de cliënt medegedeeld die daarop ook kan reageren.

Het is mogelijk dat de modellen in de praktijk niet zo eenduidig worden toegepast. Uit de literatuur ${ }^{3,20}$ weten we dat beoordelende artsen pragmatisch omgaan met de hen ter beschikking staande instrumenten. Dat valt echter buiten het bestek van dit artikel.

Overeenkomsten tussen de modellen

1. De modellen bouwen voort op de argumentatieve claimbeoordeling.

2. Bij alle modellen wordt ervan uitgegaan dat mogelijkheden worden gezocht, naast beperkingen. 
3. Het waarheidscriterium is dat van plausibiliteit (is het aannemelijk dat de aangedragen gegevens feitelijk bestaan) en consistentie (zonder tegenspraak in de aangifte door de cliënt, in overeenstemming met medische en sociaal-wetenschappelijke inzichten).

4. Bij alledrie is de beoordeling weliswaar medisch maar vooral ook meer dan medisch, multifactorieel.

5. Alle gebruiken een semi structuur, zij het in wisselende mate.

\section{Verschillen tussen de modellen}

1. Voor het MBG is het gesprek een test, de MCA is meer een dialoog en de BGB herinnert aan een vragenlijst.

2. Er wordt verschillend omgegaan met spontane opmerkingen en inadequate antwoorden: erop doorvragen (BGB en MCA) of vasthouden aan de semi structuur met samenvattingen (MBG).

3. Er wordt wel (MBG, MCA) of geen (BGB) empowerment nagestreefd, d.w.z. een relatie met de werknemer opbouwen waarin wordt samengewerkt en waarbij de werknemer actief participeert in het onderzoeken van en het oplossingen bedenken voor zijn/haar gezondheidsproblemen.

4. Bij MBG wordt nagestreefd om een zeer grondig beeld op te bouwen alvorens een oordeel te vormen. Bij de BGB wordt doelgericht gewerkt naar het bepalen van beperkingen en mogelijkheden. Dat neemt minder tijd. De MCA heeft een middenpositie hierin.

5. Doel: alleen invullen van de FML (BGB) of ook bevorderen van zelfinzicht, herstelgedrag en werk zoeken.

Deze overeenkomsten tussen de modellen blijken gebaseerd te zijn op een aantal uitgangspunten. Deze uitgangspunten zijn onderwerp van de tweede onderzoeksvraag.

\section{RESULTATEN VRAAGSTELLING 2: WAAROP ZIJN DE MODELLEN GEBASEERD?}

De overeenkomsten en verschillen tussen de modellen hebben te maken met opvattingen van de opstellers over regelgeving en over wetenschap. Deze opvattingen zijn in de ontwikkeling en de beschrijving van de modellen niet expliciet gemaakt en ook niet wetenschappelijk onderbouwd. De beschrijvingen zijn sterk gebaseerd op ervaringen in de praktijk. De tijdens de interviews ingebrachte uitgangspunten zijn veelal gemeenschappelijk en verschillen lijken vooral gradueel te zijn en de. Echte validering van de modellen heeft niet plaats gehad tot nu toe. Op basis regelgeving en wetenschap is wel iets te zeggen over de aannemelijkheid van de volgende uitgangspunten.

1. De opstellers gaan allen uit van de argumentatieve claimbeoordeling, dat wil zeggen het beoordelen van de claim op basis van de argumenten die de cliënt ervoor aandraagt. Dat is in lijn met de constatering in het RGO-advies ${ }^{8}$ dat alleen deze benadering heeft geleid tot instrumenten voor de beoordeling.

2. De gespreksmodellen sluiten alledrie aan bij de moderne opvatting dat het zaak is om niet alleen naar beperkingen te kijken maar de schatting met name te baseren op mogelijkheden. Het werkproces bij UWV, met name de Functionele MogelijkhedenLijst dwingt daar ook toe.

3. Het criterium van waarheid (plausibiliteit en consistentie) is in overeenstemming met het Schattingsbesluit21 en voor die tijd met de richtlijn MAOC. ${ }^{22}$

4. De modellen staan alle voor een multifactoriële, dat wil zeggen meer dan monocausaal medische, benadering. Er is dan ook een veelheid aan onderwerpen te vinden in de modellen. Die onderwerpen zijn allemaal wel van belang voor het krijgen van een beeld van het functioneren van een cliënt, ${ }^{21,23}$ maar de afbakening ervan en de keuzes erin zijn niet getoetst. Hoe uitgebreid is bijvoorbeeld het onderwerp Motivatie in de MBG en in hoeverre overlapt dat met Ervaren Beperkingen in de BGB of Persoon in de MCA? Tussen de modellen is veel overlap te vinden in de te behandelen onderwerpen waarbij MBG het meest gedetailleerd is in de beschrijving en de MCA het minst.

5. De modellen besteden alle aandacht aan de positie van de cliënt in het gesprek. De cliënt moet verantwoorden waarom hij niet of maar gedeeltelijk werkt (zijn claim) en meewerken aan de beoordeling. De beoordelaar moet nagaan in hoeverre de door de cliënt ingebrachte informatie juist is dan wel is te veranderen of aan te vullen. Algemeen wordt aangenomen dat deze posities consequenties hebben voor de informatieverzameling en de oordeelsvorming. Daarbij wordt gedacht aan maskeren of overdrijven van klachten, beperkingen en mogelijkheden al dan niet met boze intenties. ${ }^{24} \mathrm{~W}$ at die consequenties voor de informatieverzameling precies zijn, moet nog empirisch worden vastgesteld: mogelijk komt misleiding op grond van ziekte veel voor maar mogelijk ook vrijwel niet. ${ }^{25}$ Het is ook nog de vraag of iemand die zegt niet te kunnen werken, bang is dat werken zijn gezondheid zal schaden, het onredelijk vindt om gezien zijn situatie van hem te verwachten dat hij zal gaan werken óf dat hij niet wil werken. In de verschillende gespreksmodellen vinden we de positionele aspecten terug in de manier waarop in de 
introductie de relatie beoordelaar-beoordeelde moet worden vormgegeven, de onderwerpen die aan de orde moeten worden gesteld en de wijze waarop dat moet gebeuren.

6. Het goed hanteren van de relatie vraagt volgens de modellen specifieke technieken. De relatie is o.a. afhankelijk van de taak- en rolopvatting van zowel cliënt als verzekeringsarts. Is uitgangspunt een artspatiëntrelatie (vooral MCA) of is er sprake van een mondige cliënt met eigen doelen (vooral MBG), die samen met de arts een probleem oplost? ${ }^{26}$ Dit laatste zal de voorkeur hebben als de doelen van beoordelaar en cliënt overeenkomen. De BGB gaat hier het minst van uit. Naarmate beoordelaar en cliënt sterker van mening verschillen over de uitkomst van de beoordeling, verloopt het beoordelingsproces naar een belangenconflict, dat door middel van conflictgedrag beslecht moet worden. ${ }^{27}$

7. De belangrijke rol van conflicthantering komt ook tot uiting in de nadruk die dit onderwerp krijgt in opleiding, modellen en trainingen. De relationele component komt in de literatuur naar voren als mogelijke verklaring voor verschillen tussen beoordelaars. ${ }^{7,9}$ Als bijvoorbeeld de interactie met de cliënt slechter verloopt, wordt de kans groter dat men klachten/symptomen als moeilijk objectiveerbaar beschouwt. De drie modellen zijn hierin niet duidelijk verschillend.

8. De gesprekken zijn alle op te vatten als vormen van toetsing van de mogelijkheden die de cliënt ziet. Juridisch wordt daar een argument voor gevonden in de overweging dat als iemand een claim indient hij die moet kunnen toelichten. Een ander argument is dat de cliënt zijn eigen situatie het best kent. In twee recente proefschriften ${ }^{5,28}$ werd duidelijk dat de betrouwbaarheid van zelfbeoordeling discutabel is. Empirisch moet de waarde van zelfbeoordeling in beoordelingen nog wel worden vastgesteld. Als uitgangspunt voor de beoordelingsgesprekken is dat dus een punt van zorg voor de verzekeringsarts. Een ander argument voor het toetsen van de zelfbeoordeling is dat de cliënt zijn eigen mogelijkheden beter zal benutten als hij zich gehoord weet in de beoordeling en het idee heeft daar een eigen inbreng in te hebben gehad. In de literatuur over empowerment wordt dat principe wel bevestigd: naarmate cliënten in besluitvorming meer participeren neemt hun empowerment toe. ${ }^{29}$ Of dat ook geldt bij de claimbeoordeling arbeidsongeschiktheid is niet uitgezocht.

9. In alle modellen wordt een combinatie voorgestaan van semi-structurering en doorvragen op indicatie. De mate waarin dat voorgestaan wordt, verschilt.
Semi-structurering ligt om een aantal redenen voor de hand. Ten eerste is het een efficiënte wijze om tot de kern van problemen te komen, als die problemen in zijn algemeenheid voor de beoordelaar bekend terrein zijn. Ten tweede voorkomt semi-structurering dat de beoordelaar te snel in zijn eigen valkuil stapt, bijvoorbeeld omdat hij door zijn ervaring al heel snel meent te weten hoe het zit en zodoende onverwachte informatie of afwijkende informatie niet aan bod laat komen en zelf een beeld gaat vormen. ${ }^{30}$ Ten derde is semi-structurering een manier om gevallen vergelijkbaar te maken: bij het steeds hanteren van een aantal gelijke vragen ontstaat er sneller zicht op de eventuele afwijkendheid van de presentatie van de cliënt. Het gebruik van het gesprek als test bij het MBG berust mede hierop.

10. Er zijn tussen de modellen verschillen te vinden in taakopvatting. Het is altijd de vraag hoe uitgebreid het onderzoek moet zijn om adequaat te kunnen worden genoemd. Alledrie de modellen geven aan op hun eigen wijze naar efficiency te streven, met behoud van grondigheid. Uit de beschrijvingen komt echter naar voren dat het MBG het meest uitgebreid lijkt te zijn en de BGB het meest doelgericht. Hoe dat in de praktijk uitpakt en op basis waarvan men dan zou kiezen voor het ene of het andere model is niet bekend.

11. Een ander verschil in taakopvatting betreft de vraag of de beoordelaar alleen gericht moet zijn op het doen van een uitspraak over de claim of ook op het verder helpen van de cliënt. De BGB opteert voor het eerste, de MCA het meest nadrukkelijk voor het tweede. In hoeverre één der modellen hierin het meest effectief is, is niet bekend.

\section{BESCHOUWING}

In de vergelijking tussen de voor de beoordeling zo belangrijke gespreksmodellen vinden we overeenkomsten en verschillen. Het is een stap vooruit te noemen dat de modellen nu vergelijkbaar zijn en daarmee ook toegankelijk voor evaluatie. Het is opmerkelijk dat die evaluatie nog helemaal niet heeft plaats gevonden. Ook is opmerkelijk dat de theoretische en empirische fundering van de modellen zo impliciet is. Het feit dat dit zo is, geeft voeding aan de gedachte dat de beoordeling plaats vindt in een black box en daarmee aan de gedachte dat de cliënt mogelijk onvoldoende in de gelegenheid is om zijn recht te halen. Voor de professionele status van de verzekeringsgeneeskunde is het wenselijk als het instrument van het beoordelingsgesprek op een transparante en zoveel mogelijk gevalideerde wijze wordt ingezet. Dat is nu 
onvoldoende het geval. Dat wil niet zeggen dat de dokters maar wat doen; dat komt ook uit de vergelijking van de modellen niet naar voren. De interpretatie van de wet en de medische benadering lijken bijvoorbeeld tussen de modellen goed overeen te komen en ook goed verdedigbaar te zijn. Gedragswetenschappelijke en verzekeringsgeneeskundige opvattingen lopen echter meer uiteen. De relationele aspecten van de modellen en de (mate van) structurering zouden in de praktijk reëel verschil kunnen uitmaken. Sommige uitgangspunten lenen zich goed voor empirisch onderzoek, bijvoorbeeld de waarde van bepaalde gesprekstechnieken voor de oordeelsvorming. De discussie over de taakopvatting raakt aan dilemma's welke inherent zijn aan het vak en die het best in de vorm van consensusvorming zijn te hanteren. ${ }^{31,32}$ Daarmee kunnen de verzekeringsartsen telkens weer aan passen aan de sociaal politieke realiteit van de tijd waarin ze leven. ${ }^{33}$

\section{CONCLUSIES}

1. De drie modellen hebben naast verschillen ook veel overeenkomsten.

2. Er is geen bewezen best model, zelfs geen bewezen goed model.

3. De onderliggende principes, zoals plausibiliteit en consistentie als waarheidscriteria, relationele zorgvuldigheid, de multifactoriële benadering en de semistructurering is aannemelijk maar behoeft empirisch ondersteuning in de situatie van de WAObeoordeling.

4. Een aantal verschillen tussen de modellen zoals de vraag of alleen beoordeling nodig is of ook activering, en de vraag naar de efficiency van de beoordeling, gaat over de gewenste invulling van het vak. Dit vraagt eerder om consensusontwikkeling binnen de beroepsgroep en met UWV.

\section{AANBEVELINGEN}

Wij denken dat de gespreksvoering aan de hand van deze modellen een middel kan zijn voor professionalisering van de verzekeringsgeneeskunde. De drie modellen berusten op min of meer aannemelijke uitgangspunten. Toetsen van die uitgangspunten in de verzekeringsgeneeskunde is echter gewenst zodat de praktijk gedragen zal worden door de wetenschap. Parallel daaraan kan de beroepsgroep algemene criteria voor een beoordelingsgesprek ontwikkelen. Dat is namelijk niet alleen een zaak van wetenschap maar ook van consensus ontwikkeling aangaande de gevraagde diepgang, efficiency en normen in het vak. Nader onderzoek naar de verschillen van de modellen in hun effect is eveneens gewenst, evenals naar het praktische gebruik dat verzekeringsartsen er van maken. Het is zeer de vraag of ooit één model zal kunnen worden gekenschetst als bewezen het best maar wel kan worden bereikt dat een beoordeling beter onderbouwd en verantwoord kan worden dan nu het geval is.

Belangenconflicten: geen gemeld Financiële ondersteuning: NVVG en de WOSM Foundation

\section{LITERATUUR}

Commissie Arbeidsgeschiktheid. Werk maken van arbeidsgeschiktheid. Doetichem: Elsevier, 2001.

Razenberg PPA. Verzekeringsgeneeskundige oordeelsvorming [proefschrift]. Amsterdam: UvA, 1992.

Bont A de, Berendsen L, Boonk M, Brink J van den. In de spreekkamer van de verzekeringsarts. Een onderzoek naar het verzekeringsgeneeskundige deel van de WAO claimbeoordeling. Zoetermeer: CTSV, 2000.

Kerstholt JH, Boer WEL de, Jansen NJ. Disability assessments: effects of response mode and experience. Disabil Rehabil 2006; 28: $111-115$.

Brouwer S. Disability in chronic low back pain [proefschrift]. Groningen: RU Groningen, 2004.

Landelijk Instituut Sociale Verzekeringen. Standaard onderzoeksmethoden. Amsterdam: Lisv, 2000.

Mul CAM et al. Kwaliteit van de oordeelsvorming. Hoofddorp: TNO Arbeid, 1999.

Raad voor Gezondheidsonderzoek. Advies verzekeringsgeneeskunde. Den Haag: RGO, 2004.

Willems JHBM, Kroneman H. Arts of advocaat: nieuwe WAO verandert de rol van de verzekeringsarts. Med Contact 2003; 58: 337-340.

Boer WEL de, Brenninkmeijer V, Besseling JJM. Claimbeoordeling in het buitenland: lessen voor de nieuwe WAO. SMA 2004; 59: 408-413.

Boer WEL de, Duin JA, Herngreen H. Handleiding Methodisch Beoordelingsgesprek. Utrecht: NSOH, 1997.

Boer WEL de, Meijers JM, Verhoeff M. De MultiCausale Analyse: theorie en praktijk. Hoofddorp: TNO Arbeid, 2000.

Herngreen H, Boer WEL de. Handleiding Verzekeringsgeneeskundig beoordelingsgesprek. Utrecht: SSG, 1988.

Spanjer J. BelastbaarheidsGerichte Beoordeling. Amsterdam: Lisv, 2000.

Wijers JHL. Handicap en integratie. Handicap en Beleid 1996; 3(2): 20-22.

Molen HT van der, Kluytmans F, Kramer F. Gespreksvoering, vaardigheden en modellen. Groningen: Wolters Noordhoff, 1995.

Spanjer J. De reproduceerbaarheid van WAO-beoordelingen, een literatuuronderzoek. Tijdschr Bedrijfs Verzekeringsgeneeskd 2001; 9: 195-198.

Spanjer J. De inter- en intra-beoordelaarsbetrouwbaarheid van WAO beoordelingen. Tijdschr Bedrijfs Verzekeringsgeneeskd 2001; 9: 234-241.

Boer WEL de, Brenninkmeijer V, Zuidam W. Long term Disability arrangements. Hoofddorp: TNO Arbeid, 2004.

Horstman et al. Standaarden en het rechtskarakter van de sociale verzekering. Amsterdam: Lisv, 1997.

Besluit van 8 juli 2000 tot vaststelling van een algemene maatregel van bestuur houdende nieuwe regels betreffende de vaststelling 
van de mate van arbeidsongeschiktheid ingevolge de Wet op de arbeidsongeschiktheidsverzekering, de Wet arbeidsongeschiktheidsverzekering zelfstandigen en de Wet arbeidsongeschiktheidsvoorziening jonggehandicapten (Schattingsbesluit arbeidsongeschiktheidswetten) Staatscourant 307, 2000.

Richtlijn Medisch Arbeidsongeschiktheidscriterium. Amsterdam Lisv, 1996.

Wereld gezondheidsorganisatie. Internationale Classificatie van Functioneren en Gezondheid. Genève: WHO, 2001.

Aylward M. Origins, practice and limitations of disability assessment medicine. In: Halligan PW, Bass C, Oakly DA. Malingering and illness deception. Londen: OUP, 2003, pp. 287-299.

Halligan PW, Bass C, Oakly DA. Malingering and illness deception. Londen: OUP, 2003.

Meershoek A. Weer aan het werk. Amsterdam: Thela Thesis, 1999.

Nauta A. Oog om oog en baas boven baas. Interactiepatronen bij interpersoonlijk conflict op bureaucratische en organische organisatie-afdelingen [proefschrift]. Groningen: RU Groningen, 1996.

Reneman MF. Functional capacity evaluation in patients with chronic low back pain: reliability and validity [proefschrift]. Groningen: RU Groningen, 2004.

Itzhaky H, Schwartz C. Empowering the disabled: a multidimensional approach. Int J Rehabil Res 1998; 21: 301-310.

Pennington N, Hastie R. The story model for juror decision making. In: Hastie R, editor. Inside the Juror; The psychology of juror decision making. New York: Cambridge University Press, 1993, pp. 192-221.

Teulings CN, Veen R van der, Trommel W. Dilemma's van de sociale zekerheid. Den Haag: VUGA, 1997.

Weel ANH; Kelder MJ; Nauta AP. Praktijkdilemma's voor bedrijfs- en verzekeringsartsen. Houten: Bohn Stafleu van Loghum, 2005.

Stone D. The Disabled State. London: Mac Millan, 1985. 